\title{
Kernos
}

Revue internationale et pluridisciplinaire de religion grecque antique

$23 \mid 2010$

Varia

\section{Yulia USTINOVA, Caves and the Ancient Greek Mind. Descending Underground in the Search for Ultimate Truth}

\section{André Motte}

\section{(2) OpenEdition}

\section{Journals}

Édition électronique

URL : http://journals.openedition.org/kernos/1645

DOI : 10.4000/kernos. 1645

ISSN : 2034-7871

\section{Éditeur}

Centre international d'étude de la religion grecque antique

\section{Édition imprimée}

Date de publication : 1 janvier 2010

Pagination : 394-395

ISSN : 0776-3824

\section{Référence électronique}

André Motte, "Yulia ustinova, Caves and the Ancient Greek Mind. Descending Underground in the

Search for Ultimate Truth », Kernos [En ligne], 23 | 2010, mis en ligne le 15 septembre 2011, consulté le 21 septembre 2020. URL : http://journals.openedition.org/kernos/1645 ; DOI : https://doi.org/ 10.4000/kernos. 1645

Ce document a été généré automatiquement le 21 septembre 2020 


\title{
Yulia USTINOVA, Caves and the Ancient Greek Mind. Descending Underground in the Search for Ultimate Truth
}

\author{
André Motte
}

\section{RÉFÉRENCE}

Yulia USTINOva, Caves and the Ancient Greek Mind. Descending Underground in the Search for Ultimate Truth, Oxford, Oxford University Press, 2009. 1 vol. $14,5 \times 22,5 \mathrm{~cm}, 315$ p. ISBN : 978-0-19-954856-9.

1 Comme l'indique son sous-titre, cette remarquable étude n'ambitionne pas d'explorer sous tous rapports la place que tiennent les grottes dans la vie et la pensée des anciens Grecs, mais de montrer le rôle que, bien souvent, ces espaces sont censés jouer dans la quête d'une vérité ultime, éprouvée comme une révélation divine. C'est donc bien à l'étude d'un thème important relevant de la pensée religieuse que ces pages sont vouées.

2 Après une introduction qui précise l'objet de l'enquête et en esquisse la méthodologie, un premier chapitre, très original, s'attache à éclairer les phénomènes qui vont être étudiés en les rapprochant de certaines recherches contemporaines d'anthropologie et de neuropsychologie: la présence dans de nombreuses sociétés, tant modernes qu'anciennes, d'expériences diverses visant à atteindre des états de conscience modifiés dans lesquels on éprouve la révélation d'une vérité transcendante, le sentiment de toucher à l'ineffable, voire de vivre une union mystique à la divinité. Ces expériences supposent souvent un séjour dans un espace obscur et séparé du monde, avec une interruption de l'activité sensorielle qui fait place à des rêves et à des visions intérieures. Parfois, sans parler ici des drogues, c'est par la respiration d'un gaz à l'effet 
euphorisant ou produisant des troubles psychiques, ce qui suppose aussi un espace clos, que ces états de conscience sont atteints. Aussi bien cavernes, grottes et autres espaces souterrains apparaissent-ils souvent comme des lieux privilégiés où opèrent prophètes et magiciens. D'autre part, ces recherches ont aussi pris en compte les récits d'une approche de la mort (near-death) qu'ont pu faire certains hommes et qui évoquent volontiers un voyage que leur l'âme, séparée du corps, a effectué en passant par un tunnel obscur avant d'apercevoir une resplendissante lumière.

On a tôt fait de rapprocher certains faits grecs de ces expériences dont les nouvelles sciences de l'homme ont montré l'omniprésence dans les sociétés issues de l'homo sapiens. Un intérêt de ce rapprochement est qu'il invite à prendre au sérieux les témoignages du genre que procure le domaine hellénique, c'est-à-dire à reconnaître la réalité psychologique de certains d'entre eux à tout le moins, plutôt que de les tenir pour des fictions auxquelles les Anciens eux-mêmes n'auraient pas prêté foi. D'autre part, si l'on admet que c'est la nature même de l'espèce humaine qui prédispose à de telles expériences, point n'est besoin de postuler l'influence de sociétés voisines où sont attestées des pratiques chamaniques pour rendre compte de la présence en Grèce de phénomène identiques ou similaires.

Les chapitres suivants sont consacrés à une revue systématique et méthodique des faits grecs regroupés en quatre catégories. La première concerne les oracles institutionnalisés et autres lieux où se pratique la divination inspirée. Les Nymphes ainsi que Pan, familiers des grottes et souvent réunis, fournissent un bon nombre de cas, à commencer par la fameuse grotte de Vari où un nympholepte pratique la divination et proclame sa dévotion dans des inscriptions. Des grottes marquent aussi parfois l'entrée de l'Hadès, comme au cap Ténare et dans les célèbres sanctuaires oraculaires de Trophonios et d'Amphiaraos, sans oublier des personnages auréolés de légende comme Zalmoxis et l'Orphée de Lesbos. Mais c'est à Apollon que l'A. consacre la plus grande part de ce chapitre en soulignant le fait paradoxal que ce dieu de la lumière se complaît dans les antres quand il s'agit de vaticiner, comme on peut le voir à Claros, au sanctuaire du Ptoion, à Délos, en Thrace, à Paphos et bien sûr à Delphes. À noter ici que l'A. reconnaît dans l'adyton une grotte artificielle et plaide pour la réalité d'un pneuma émanant de la roche. Consacré aux prophètes et aux poètes, le chapitre suivant traite de la Sibylle et de personnages aveugles qui fréquentent des grottes, l'idée étant que ce retranchement du monde et cette perte sensorielle sont comme la condition d'une inspiration divine. Beaucoup plus développé et plus substantiel aussi est le chapitre voué aux sages et aux philosophes. C'est qu'ici la nature et l'abondance des témoignages, dus parfois aux auteurs eux-mêmes, permettent notamment des rapprochements plus circonstanciés avec certaines données qu'exploite la neuropsychologie. À juste titre, l'A. met en garde contre l'habitude qu'ont les modernes de minimiser l'importance de l'idée de révélation dont se réclament certains penseurs anciens, sous prétexte qu'une telle conception serait incompatible avec le discours rationnel qu'ils initient. Avant les philosophes, il y a eu des sages comme Épiménide et Phérécyde dont les biographies légendaires comptent maints éléments que le sujet traité incite à prendre en compte. On peut en dire autant, et même davantage, du philosophe Pythagore, mais c'est Parménide, dévot d'Apollon et père des philosophes au dire de Platon, qui mérite sous ce rapport la palme. L'exposé dont il bénéficie compte parmi les plus intéressants et les plus convaincants. Les pages réservées au personnage d'Empédocle ne sont pas moins suggestives. Reste un dernier chapitre centré sur les expériences de near-death, avec lesquelles, au dire de l'A., certains récits, 
comme celui d'Er l'Arménien dans la République de Platon, présentent d'évidentes analogies. Fournissent aussi une matière de grande importance les cultes à mystères, ceux d'Éleusis, ceux de Dionysos et d'Orphée, ceux d'Isis et ceux de Mithra.

5 Un lecteur pressé sera ravi de découvrir en fin de volume un récapitulatif qui, en six pages, retrace le parcours, mais ceux qui feront de l'ouvrage une lecture complète ne le regretteront pas : l'étude est remarquablement documentée, - la bibliographie compte plus de 800 titres et n'est pas d'apparat, - solidement charpentée et rigoureusement argumentée. Son ouverture aux sciences humaines trace prudemment de nouvelles perspectives et n'altère aucunement une application stricte de l'approche historicocritique. On doit souhaiter à cet ouvrage une très large audience.

\section{AUTEURS}

\section{ANDRÉ MOTTE}

Université de Liège 